\title{
Impact of the Mandatory Community Midwifery Service on the Utilization of Maternal Health Care by Women in Ondo State, Nigeria
}

\author{
Fadare R. I. ${ }^{1}$, Oyetunde M. O. ${ }^{2}$, Akpor O. A. ${ }^{1, ~ *}$ \\ ${ }^{1}$ Department of Nursing, College of Medicine and Health Sciences, Afe Babalola University, Ado-Ekiti, Ekiti State, Nigeria \\ ${ }^{2}$ Department of Nursing, University of Ibadan, Oyo State, Nigeria
}

Email address:

akporoa@abuad.edu.ng (Akpor O. A.)

\section{To cite this article:}

Fadare R. I., Oyetunde M. O., Akpor O. A.. Impact of the Mandatory Community Midwifery Service on the Utilization of Maternal Health Care by Women in Ondo State, Nigeria. Science Journal of Public Health. Vol. 3, No. 5, 2015, pp. 719-725.

doi: $10.11648 /$ j.sjph.20150305.28

\begin{abstract}
The study explored the perceived impact of the mandatory community midwifery service on utilization of maternal health care by women, using the General System Theory and the Logic Model. The research was conducted in three selected Local Government Areas (LGAs). The research design for this study was the time-series type of non-controlled experimental design. The researcher assessed records of maternal health care attendance from the selected health facilities from July 2002 to July 2011 to generate data for the study. The study population comprised of 306 women of reproductive age group (15-49) in the three selected communities (who have participated in the programme) where the three primary health care centres are located. Multistage sampling technique was adopted to select three Local Government Areas (LGAs) from where data was collected. In-depth interview guide, questionnaire and format for recording data from records were used in the study. The result obtained from the study indicated that there was no significant difference in the levels of utilization of maternal care services before and after the inception of the mandatory community service except for the slight increase in antenatal care utilization. Majority of the women expressed satisfaction with the services they received from the midwives. The study also revealed a slight increase in the levels of utilization of antenatal attendance while not much change had occurred in the use of facility based delivery care as well as postnatal care.
\end{abstract}

Keywords: Antenatal Care, Maternal Care, Community Midwifery Services

\section{Introduction}

Maternal mortality is the most extreme consequence of poor maternal health. Maternal health related complications (complications of pregnancy and childbirth) are the leading cause of disability and death among women of reproductive age (15-49 years) in developing countries.

In Nigeria, a wide geographical variation obtains with maternal mortality, with the North having a far higher maternal mortality compared to the South. The North-East zone recorded the highest figure of 1,549/100,000 which was about ten times the figure in the South-Western zone $9165 / 100,000$. In the rural area, where most Nigerians live has a higher mortality ratio of 828 deaths per 100,000 live births compared to the urban areas with 351 maternal deaths per 100,000 live births. For every maternal death, at least thirty (30) women are estimated to suffer short or long term disabilities. An estimated 800,000 women suffer vesico-vaginal fistula (VVF) from prolonged labour and complicated deliveries. It is estimated that Nigeria has the largest burden of VVF in the developing world, accounting for $40 \%$ of global estimates (WHO Partnership for Transferring Health Systems [1]. Nigeria Demographic Health Survey reported that only $61 \%$ of pregnant women received ante-natal care at least once from a trained provider while only a third $(32.6 \%)$ delivered in health facilities. The proportion of pregnant women that has skilled attendant at delivery was $35.2 \%$ while $16.9 \%$ delivered on their own with no assistance from anyone [2].

Available data indicated that maternal mortality in Nigeria was at 545 per 100,000 live births and neonatal mortality rate at 40 per 100 with majority of the deaths 
occurring in the rural communities. Twenty times the number that died suffers lasting, debilitating and often humiliating damage to their health. The unacceptably high maternal mortality in Nigeria was attributed to the dearth of skilled attendance during pregnancy and childbirth and lack of access to basic emergency obstetric care at the rural areas where most of the deaths occur [3].

Also displeased by the deteriorating status of women's health in Nigeria and in an effort to uphold and enhance government's initiative, the Nursing and Midwifery Council of Nigeria re-introduced the basic midwifery training programme in 2003. The programme is one of the government's initiatives designed to ensure that there is availability of skilled attendants at every birth in the primary health care levels with a view of improving maternal health and consequently reducing maternal mortality. The Basic Midwifery Programme was aimed at preparing competent, skilled and versatile midwifery practitioners who are capable of providing high level care to individuals and expectant families in primary health care settings, health clinics and communities in order to reduce maternal and infant morbidity and mortality.

The training programme started in Ondo State in 2003 and the first set of midwives graduated in March, 2006.The duration of the training is 36 months and it is believed that by the special educational background, the practitioner will be able to make independent judgment, manage normal midwifery, provide appropriate care including family planning and refer individuals with high risk and complications to other levels of health care. A compulsory one year community service period was also built into the programme to ensure that graduates spend one year in the community providing midwifery services to the women within the community. A complete midwifery kit containing all the equipment required to provide care within the community was given to each of these midwives.

The idea of mandatory community midwifery practice came up in Nigeria in 2003. According to Nursing and Midwifery Council of Nigeria, hospital-based maternal mortality data shows that about 800 per 100,000 women die in Nigeria in the process of giving birth with about 4,400 maternal deaths monthly. It is assumed that many more died in the communities that are not part of the available data. The unacceptably high maternal and child mortality and morbidity has been linked to shortage of skilled personnel (especially midwives) to attend to women during delivery particularly in the rural communities. This had been reported to impact negatively on the utilization of services by women [4].

A study by the World Bank officials [5], indicated that one woman was dying from pregnancy and childbirth related illness every 16 minutes in Ondo State Nigeria, despite the one-year compulsory community midwifery service that was introduced as a means to ensure the availability of midwives in the communities by the Government. It was also revealed that $84 \%$ of women were not accessing qualitative health care and shortage of trained nursing and midwifery personnel was identified as a reason. It then became appropriate to investigate the impact of the community midwifery service on the utilization of maternal health care. Also there is no available information on the advantage of the one year mandatory community midwifery service by the midwives. The study therefore was conducted to assess the perceived impact of the mandatory service on the utilization of maternal care services by the women.

Available data from Nigeria demographic and health survey [NDHS] [3], puts maternal mortality in Nigeria at 545 per 100,000 live births and neonatal mortality rate at 40 per 100 with majority of the deaths occurring at the rural community level. Twenty times the number that died suffers lasting, debilitating and often humiliating damage to their health. The study was aimed at evaluating the impact of the mandatory community service for the basic midwives between July 2006 and July 2011 on the utilization of maternal health care by women in Ondo State, Nigeria [3].

\section{Theoretical Framework}

The theoretical framework of the study was a combination of the General System Theory [6] and the Logic Model [7]. The general system theory has an underlying assumption that the whole is greater than the sum of its parts. A system consists of two or more connected component of subsystem that form an organized whole and that interact with each other to achieve desired goals. A health care facility is a social system of interdependent members (components) possessing two fundamental system features; structures or organization and function or interaction. An input-process-output feedback model is commonly used to depict the structural relationship of a system. This model illustrate that all systems have inputs or resources that when processed help the system achieve its goals or output. The feedback system theory provides a framework that offers a logical way to integrate all of the factors that influence a social system functioning and link the system together in a meaningful whole.

The logic model is used typically to depict the input, processes and outcomes associated with an organization and its programs. The model can be very useful when designing outcomes- based evaluations of programs. Logic model is best to use to depict major recurring items in the organization or program rather than one-time items so that the program would continue to produce the results desired for clients and the community.

In the context of this study, a revision and application of the General System Theory [6] and the Logic Model [7] pose viable and highly useful bases. General system theory has its main elements as input, through put (process) and output/feedback loop. Similarly the Logic Model's components include input (program activities); process (service delivery) output (immediate result; outcome, impact). Designing the basic midwifery programme, 
training the midwives and equipping them with necessary knowledge, involving them in the one year community service, mandating the midwives to live within the community during the service year, remuneration and equipping them with a midwifery kit each are all inputs. Service delivery includes all the services that the midwives are expected to offer in the communities such as family planning, deliveries antenatal care, health education home visits, postnatal care etcetera. These yield results which are categorized as immediate, outcome or impact. The impact in the context of this study is improved maternal health utilization, with emphasis on increased antenatal clinic attendance, increased deliveries and increased postnatal clinic attendance.

\section{Materials and Methods}

The research was conducted in three selected Local Government Areas (LGAs) out of the eighteen LGAs in Ondo State, Nigeria. The research design for this study was the time-series type of non-controlled experimental design. The researcher assessed records of maternal health care attendance from the selected health facilities from July 2002 to July 2010 to generate data for the study. The study population comprised of women of reproductive age group (WRAG) in the three selected communities where the three primary health care centres are located (where records of maternal health care attendance were assessed). Multistage sampling technique was adopted to select three Local Government Areas (LGAs) from where data was collected.

Sample size $(\mathrm{N})$ of the participants for the study was determined as described by earlier investigators [8]

$$
N=[z] 2 p q / d^{2}
$$

Where $\mathrm{Z}=$ the standard normal deviate at $95 \%$ confidence interval $=1.96$.

$\mathrm{p}=$ Proportion of women utilizing maternal health care services- $58 \%=0.58$.

$\mathrm{q}=1-\mathrm{p}=0.42$.

$\mathrm{d}=$ degree of precision $=0.1$

$\mathrm{N}=[1.96] 2 * 0.58 * 0.42 / 0.01=93.58$

$N=[1.96] * 2 * 0.58 * 0.42 / 0.1^{2}=93$ per community

$93 * 3=279$

Ten percent of the desired sample size was added to the calculated sample size because of high attrition and nonresponse, thus $\mathrm{N}$ was 306 .

From each community, resident houses were selected through systematic random sampling technique while total sampling was used to recruit eligible participants from each selected house for the study. In-depth interview guide and format for recording data from records were used in the study. The interview guide was in was divided into two sections. Section A asked for the demographic characteristics of participants. Section B was a checklist that sought to explore the participants' opinions on the mandatory community service. Lastly, a format/checklist was developed to record data from records (antenatal care attendance, deliveries and postnatal care attendance between July 2002 and July 2011).

The researcher obtained an introductory letter from the Nursing Department to the study settings for permission. A copy of the research proposal was submitted to the Research Review Committee of the Ondo State Ministry of Health and ethical approval was obtained to conduct the study in the State. Written and verbal informed consent was sought and obtained from participants before administration of the questionnaire. Participation was made voluntary without coercion, manipulation or undue inducement. The participants were told that they could freely withdraw at any point during the study process.

Both primary and secondary data were used. Research assistants were trained to enter the communities for data collection. The researchers and the trained assistants administered questionnaire to the participants. Permission was obtained from the heads of the households in each community to administer the questionnaire. The research assistants moved from house-to-house based on the identified household in the sampling list to administer the questionnaire. All eligible women found in the selected households were involved. This process was carried out until the desired number of women was achieved.

There were 306 women recruited for the study out of which 282 responded adequately to the questionnaire. The questionnaires were retrieved from the participants immediately after completion. The secondary data was collected by the researcher from records of the selected health centers in the selected wards. The data covered the period between July 2002 and July 2011. Data from the study was analyzed using both descriptive and inferential statistics.

\section{Results}

There were 306 women recruited for the study out of which 282 responded adequately to the questionnaire and the data obtained was analyzed. Table 1 shows the analysis of the socio-demographic status of the participants (women in reproductive years), the majority of the participants 113 (40\%) were between the ages of 15 and 25 years. The highest proportion of the participants $275(86 \%)$ were married. In term of educational status of the participants $86(30.5 \%)$ had secondary school education and $53(18.8 \%)$ with no formal of education. With respect to participants occupation, the majority $148(52 \%)$ were civil servants while 24 (9\%) were full-time housewife. The distributions by religion revealed that $162(57 \%)$ were Christians while the remaining 120 (43\%) were Muslims. Lastly, regarding the participants parity, the majority $94(33 \%)$ had 3 children respectively and 32 (11\%) had 5 children each (Table 1). The age distribution of the participants (women). The age range was 33.00 years, the age mean was 28.86 while the standard deviation was 7.96 . 
Table 1. Demographic characteristics of participants (Women).

\begin{tabular}{lll}
\hline $\begin{array}{l}\text { Socio demographic } \\
\text { characteristics }\end{array}$ & Number & Percentage (\%) \\
\hline AGE & N $=282$ & \\
$15-25$ & 113 & 40 \\
$26-35$ & 95 & 34 \\
$36-45$ & 69 & 25.5 \\
$46-49$ & 5 & 1 \\
Marital status & & \\
Single & 1 & 2 \\
Married & 275 & 86 \\
Separated & 3 & 6 \\
Divorced & 2 & 4 \\
Widowed & 1 & 2 \\
Educational level & & \\
None & 53 & 18.8 \\
Primary & 78 & 27.7 \\
Secondary & 86 & 30.5 \\
Tertiary & 65 & 23.0 \\
Occupation & & \\
Farming & 33 & 12 \\
Housewife & 24 & 9 \\
Student & 15 & 5 \\
Civil servant & 148 & 52 \\
Artisan & 39 & 14 \\
Business & 23 & 8 \\
Religion & & \\
Christianity & 162 & 57 \\
Islam & 120 & 43 \\
Parity & & \\
1 & 23 & 29 \\
2 & 78 & 18 \\
3 & 94 & \\
4 & 52 & \\
5 & 32 & \\
6 & & \\
\hline & & \\
\hline
\end{tabular}

The perception of the women about the community midwifery service revealed the following responses:

"They are still young and very small"

"So they are hardworking"

"They are always available at the centre"

"Some of them are kind while some of them are not jovial at all"

"They are ready to help you anytime"

"They are friendly but they need better experience"

"They newly left school so their brains are still sharp"

"The midwives are tender hearted"

"They treated me well when I had my last baby (2 years old)"

"They are after our wellbeing so they teach us new things"

"I am new her but my little experience is that they are okay"

"They are here for our health safety and that is what they are after"

"I use to enjoy the way they were teaching us with demonstrations"

With respect to the services enjoyed by the participants in the centre as compared to the period prior to the arrival of the midwives, revealed the following responses:

"The midwives now come to our houses to encourage us to clean our environment"

"They teach us to eat good food in the clinics and why it is necessary for us"

"They perform examination on us from head to toe and not only the abdomen alone"

"They use to demonstrate to us how to put our babies to breast"

"They give us lectures on importance of family planning"

"They have taught us how to care for the baby's cord in a new way"

"Women can come to the centre for care anytime even in the night and they are always there"

"They now encourage our husband to follow us when we want to deliver"

"The midwives don't abuse us like before"

In the case of utilization of the health centre by the women, when compared to the period prior to the arrival of the midwives, the participant's responses include the following:

"More women are now coming to the health centre for treatment and clinics

"Because of the distance, many women have difficulty assessing the health centre" "Women do not like coming to the centre"

"Women only go there for antenatal clinics not for delivery"

"Because of the free family planning services lot of women are now going to the

Centre"

The impact of the midwives on women attendance at the primary health care centre received the following responses from the participants:

"Yes, they have made a lot of changes"

"Though they are trying, there has not been much change"

"They could have made some changes but the clinic is too far"

"They could have made some changes but they don't have instruments"

"To me, I can't see any improvement over few years ago"

In assessing the impact of the midwives on the health of women in the community, some of the responses revealed the following:

"Honestly, the midwives are competent and the women are happy with them"

"They perform home visits to encourage the women to come to the centre for delivery"

"They do follow up visits"

"They use to refer anybody that her case is serious to the state hospital"

"Our women now know some danger signs of pregnancy and what to do immediately"

"They have taught us the importance of good nutrition"

"They use to involve the community leaders and women in meetings concerning our health"

"People in the community now know the dangers of circumcising female babies"

"The midwives are always available even in the nights to attend to emergencies"

The challenges hindering the women from accessing 
health services at the centre, as indicated by the participants include indicated to be lack of belief in medical services, lack of drugs and equipment, lack of adequate midwives and lack of sanitation equipment. The responses from participants were as follows:

"Majority of our women don't believe in medical services"

"There are no drugs/equipment in the centre"

"Some women think the midwives are young and inexperienced"

"Though the midwives are hardworking but they are not enough to care for people"

"The fear that lack of clean water at the centre to wash instrument can transfer HIV"

When asked on how they think challenges encountered at the centre can be improved, participants indicated the need for posting of more midwives to the centre, provision of drugs and equipment, provision of water and sanitation facilities and health education. The following were some of the responses:

"Government should post more midwives to the centre"

"Drugs and equipment should be provided"

"Government should make sure that borehole is given to the centre"

"Midwives should intensify their health education"

"Other women that have enjoyed services at the centre should encourage others"

As shown in Table 2, the data recorded from the centres on the numbers of antenatal care attendance, facility based deliveries and post-natal care attendance between July 2002 and July 2011 revealed steady increases in in number antenatal visits from 2006 till 2011, for study Area 'A'. The number of antenatal visits for study Areas ' $B$ ' and ' $C$ ' did not follow any particular pattern although highest number of visits were recorded in 2005 and 2011, respectively (Table 2).

Table 2. Data of maternal health care services utilization from P.H.C. Arakale, Akure South LGA.

\begin{tabular}{|c|c|c|c|c|c|c|c|c|c|c|}
\hline \multirow{2}{*}{$\begin{array}{l}\text { Services } \\
\text { A }\end{array}$} & \multicolumn{5}{|c|}{ Period before the inception of mandatory service } & \multicolumn{5}{|c|}{ Period after the inception of mandatory service } \\
\hline & & & & & & & & & & \\
\hline & 2002 & 2003 & 2004 & 2005 & 2006 & 2007 & 2008 & 2009 & 2010 & 2011 \\
\hline Number of antenatal clinic attendance & 473 & 4477 & 5330 & 3788 & 3145 & 4561 & 6442 & 6712 & 6948 & 5706 \\
\hline Number of facility based deliveries & 259 & 514 & 543 & 544 & 400 & 496 & 627 & 802 & 954 & 10376 \\
\hline Postnatal clinic attendance & NR & NR & NR & NR & NR & NR & NR & NR & NR & NR \\
\hline \multicolumn{11}{|l|}{ B } \\
\hline Number of antenatal clinic attendance & NR & NR & NR & 919 & 846 & 706 & 693 & 770 & 809 & 793 \\
\hline Number of facility based deliveries & NR & NR & NR & 96 & 77 & 57 & 60 & 58 & 68 & 56 \\
\hline Postnatal clinic attendance & NR & NR & NR & 189 & 192 & 157 & 169 & 168 & 188 & 146 \\
\hline \multicolumn{11}{|l|}{$\mathrm{C}$} \\
\hline Number of antenatal clinic attendance & 1578 & 1884 & 3956 & 4015 & 4372 & 4291 & 3241 & 2773 & 2487 & 5631 \\
\hline Number of facility based deliveries & 145 & 141 & 256 & - & 262 & 337 & 214 & 143 & 290 & 293 \\
\hline
\end{tabular}

'NR' indicate no record found. 'A', 'B' and 'C' represent the three Local Government Areas used for the study.

\section{Discussion}

The study showed that the reproductive age group with the highest frequency was 15-25 years. This may be closely associated with the effect of western education in the South West zone of Nigeria where most of the girls do not enter into marital relationship until they have attained at least secondary level of education. This can be confirmed with the high level of educated women among the participants $(30.5 \%$ and $23 \%)$ had attended secondary and tertiary levels of education respectively while only about $18.8 \%$ had no education.

Almost all the participants were married. Looking at the participants' occupation, the group with the highest frequency $(52 \%)$ were civil servants. The high frequencies in these two characteristics, that is, education and occupation may be closely related to the assertion that women's education and wealth index may be important determinants in the utilization of maternal care services [9].

This finding was also confirmed by Babalola and Fatusi [10], that there was a significant association between education and each of the three indicators of maternal care services in that education enhances higher level of health awareness and greater knowledge of available health services, improve ability of women to afford the cost of medical health care and freedom to make health related decisions including choice of maternal services to use.

On their experience with the midwives, majority of the participants gave responses like "some of them are kind", "they are friendly", "they are kind hearted", "they treated me well when I had my last baby about three years ago", "they are after our health safety", "I used to enjoy the way they were teaching us with demonstrations". However, some participants' believed the midwives are inexperienced, not jovial or are too young. On the type of services enjoyed by the participants now as compared to prior the arrival of the midwives, the responses all clamoured around the following themes- health education on good nutrition and environmental hygiene, care of the children, availability of the midwives even at nights, good interpersonal relationship, breastfeeding and family planning counseling.

On the extent of utilization of the health centres by 
women as compared to the period prior the arrival of these midwives. Fifty percent $(50 \%)$ of the participants believed that more women are now patronizing the centre for treatment and various clinics most especially for family planning services. However, some did not like going to the centre at all due to difficulty in accessing the centre, some said they liked going there for antenatal clinics but not for delivery. Also the high increase in patronage of antenatal care might be attributed to the friendly attitude of the midwives as corroborated by [11] that the attitude of the skilled personnel considered the most important factor in maternal service utilization.

These findings demonstrated to, some extent, the women's satisfaction with the services of the midwives as confirmed by [12] that though women receive care from family physicians and obstetricians, women were slightly more satisfied with care from midwives. On the impact of the midwives on the rate of utilization of the centres about half of the participants claimed that the presence of the midwives had made a lot of changes while half of them claimed that the midwives could have made quite a lot of changes but for distance and lack of instruments at the clinics.

The participants also perceived that the presence of the midwives had influenced the health of the women in the communities in many ways including teaching and creating awareness to healthy living, community involvement and mobilization, discouragement from female circumcision, availability of the midwives in emergency situations especially at nights and referral of identified serious cases. These findings agreed with the statutory functions of the midwife which stated that the midwife must be able to give necessary supervision, care and advice and that she has the important task in help and education [13]. The perception of the participants as regards antenatal and postnatal care is in conformity with the report of Mrisho et al., [14]. Also in their study, it was indicated that women were generally positive about both antenatal and postnatal care. Fear of caesarean section was reported as a factor hindering intrapartum care seeking from health facility.

Majority of the participants highlighted lack of drugs, equipment, inadequate number of midwives and lack of clean water which discourage women with the fear of infection transmission. These challenges were confirmed by the findings of Kamai [9] that shortage of qualified personnel, lack of equipment and quality services, may also be underlying causes of viability in service utilization. Participants also believed that there could be improvement on the identified challenges if government could post more midwives to the centres, provide drug equipment and portable water and facilitate awareness and enlightenment. As observed in this study, Fatusi and Ijaduola [15] have reported that the poor staffing of health facilities which makes it difficult to guarantee twenty-four hour service is a factor that discourages women in Nigeria even when they had received antenatal care services to seek when labour commences.

\section{Conclusion}

A time series type of non-experimental design was used to find out the output of the mandatory community service on the utilization of maternal care services in Ondo State between July 2006 and July 2011.

The result obtained from the study indicated that there was no significant difference in the levels of utilization of maternal care services before and after the inception of the mandatory community service except for the slight increase in antenatal care utilization. Majority of the women expressed satisfaction with the services they received from the midwives. However this subjective data was not justified by the statistics obtained.

The study found out that there was a slight increase in the levels of utilization of antenatal attendance while not much change had occurred in the use of facility based delivery care as well as postnatal care. Also there was no correlation between the level of antenatal care attendance and facility based deliveries before and after the inception of the mandatory community service. A majority of the women claimed that the presence of the midwives in the communities had made some improvements in their care.

The limitation of the study is the purposive and convenient sample of women living in the study area and only three Primary Health Care facilities were used out of the eighteen Local Government Areas in the State used for the study, hence the results are not generalizable to a larger content.

\section{Acknowledgement}

The authors are grateful to all who granted them permission for this study to be conducted and all participants in the study.

\section{References}

[1] PATHS, DFID and WHO. (2006). Training Manual on Life Saving Skills for Nurses /Midwives, Ibadan.

[2] National Population Commission (NPC). (2004). Nigeria demographic and health survey, 2003. Available at: http://www.dhsprogram.com/pubs/pdf/FR148/FR148.pdf.

[3] National Population Commission (NPC). (2009). Nigeria demographic and health survey, 2008. http://www.unicef.org/nigeria/ng_publications_Nigeria_DHS 2008_Final_Report.pdf.

[4] Nursing and Midwifery Council of Nigeria (NMCN). (2004). Draft of Blueprint for Basic Midwifery Education and Practice.

[5] Obadare,O. (2010). Tackling Infant, Maternal Mortality in Ondo State. Sunday Punch, June 25.

[6] Hayajneh, Y. (2007). Management for health care professionals series systems and systems theory. Management for Health Care Professionals Series. Available at: http://www.hayajneh.org/a/readings/Systems-Theory.pdf. 
[7] Kellogg, W.K. (2004). Using Logic Models to Bring Together Planning, Evaluation, and Action Logic Model Development Guide. Available at: http://www.smartgivers.org/uploads/logicmodelguidepdf.pdf.

[8] Araoye, M. O (2004). Research Methodology with Statistics for Health and Social Sciences. Ilorin. $1^{\text {st }}$ Edn, Nathadex Publishers.

[9] Kamai, M.M. (2009). Factors Affecting Utilization of Skilled Maternity Care Services Among Married Adolescents in Bangladesh. Asian Population Studies, 5(2):153-170.

[10] Babalola, S and Falusi, A. (2009). Determinant of use of Maternal Health Services in Nigeria looking beyond individual and household factors. Biomedical Central, Pregnancy and Childbirth, 9: 43.

[11] Ibeh, C. (2008). Is poor maternal mortality index a problem of care utilization?: a case study of Anambra State. African Journal of Reproductive Health, 12(2): 132-140.
[12] Kirkham, M. (2010). The Midwife-Mother Relationship. Palgrave Macmillan.

[13] Foster, I.R. and Lasser, J. (2010). Professional Ethics in Midwifery Practice. Jones and Bartlett Publishers.

[14] Mrisho, M.; Obrist, B; Schellenberg. A.J; Haws, R.A; Mushi; A.K; Mshinda, H; Tanner, M and Schellenberg, D. (2009). The use of antenatal and postnatal care: Perspectives and experiences of women and health care providers in Rural Southern Tanzania. Biomedical Central, Pregnancy and Childbirth 9:10.

[15] Fatusi, A.O. and Ijadunola, K.T. (2003). National study on essential obstetric care facilities in Nigeria, Abuja Federal Ministry of Health and United Nations Population Fund (UNFPA). 